\title{
Wired without the Barbs: Using the Internet for Rangeland Information
}

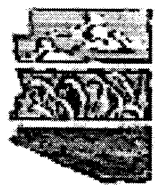

\author{
BARBARA S. HUTCHINSON AND GEORGE B. RUYLE
}

$\mathrm{W}$ hether a farmer raising pigs in Iowa, a cattle rancher in Wyoming, or rural citizens interested in their environment, all people whose livelihoods are tied to the land are participating in the same brave new world of global competition and instantaneous communication as Bill Gates and his Microsoft legions. Economic survival depends on the ability to adapt to this fast-paced and information-driven marketplace. This, coupled with growing land-use pressures and environmental constraints has placed new demands on ranchers and farmers but has also created new opportunities to better understand and utilize their natural resources. Now more than ever, issues related to environmentally sustainable stewardship, marketing, and public policy must be understood for resource management and rural development programs to successfully address the changing needs of citizens living in these communities. By taking advantage of new communications technologies, it is now possible for everyone to access relevant information on those issues that affect land management decisions.

Since the birth of the World Wide Web, it has become apparent that successful Web sites provide relevant content that is easy to navigate and searchable for specific information. It is not enough to just make Internet access, data sets and information resources available to rural communities. Such information must be combined with user-friendly interfaces and guidance for effective uses. Most users do not have time to merely surf the Internet for hours or the patience to scroll through hundreds of potentially useful sites located by a general Web browser looking for answers to specific questions. Many find the mass of information on the Web overwhelming, unorganized, and of unknown quality, which can lead to frustration and disappointment. In general, those searching Web sites want organized, reliable, easy-to-use information, and access to immediate assistance on a given subject area.

To provide these services, certain Web site projects are focusing efforts on developing value-added locations that act as a clearinghouse for information on a particular subject. Such Web sites provide quality and reliable information, both original content and annotated links to other Web sites, in a variety of formats that are organized for quick and easy access. Using this model, the Agriculture Network Information Center (AgNIC), a national-level initiative started by the National
Agricultural Library (NAL) and Land Grant universities began operation in 1995. Within the context of the growing use of the Internet by ranchers and farmers, this article describes specific resources, applications, and services available through Arizona AgNIC.

\section{The Agriculture Network Information Center (AgNIC)}

AgNIC is a subject-based, distributed electronic information system that links resources from Land-Grant universities, the National Agricultural Library, and other cooperating organizations in a "one-stop shopping center" for agricultural and related information. Originally NAL and four land grant universities (Cornell University, Iowa State University (ISU), the University of Arizona (UA), and the University of NebraskaLincoln (UNL)) developed this system. Using a "centers of excellence" approach, each institution selected subject areas in which it had particular strengths, that had application and interest for their respective constituencies, and that had national implications. Institutional Web sites were developed providing users with original text, links to reviewed Web sites, and online reference services for each of the chosen subjects.

As part of this virtual Center and for the past five years, an interdisciplinary team at the University of Arizona has designed and developed an extensive Web site on the topic of managing rangelands. The team is made up of members from three divisions in the College of Agriculture (School of Renewable Natural Resources, Arid Lands Information Center, and Network Support Group) and members of the University Library. The topic "rangeland management" was selected because it fit well into the "centers of excellence" organizational structure of the national-level initiative. Also, the Arizona team considered potential topics in terms of importance to Arizona and the West, relevance to broad regional interests, and an interdisciplinary focus that would make the topic useful to a wide range of customers. Rangeland management fit these criteria due to the extensive nature of rangelands, their environmental, economic and cultural importance and their broad appeal to the general public.

The strategy for providing electronic information on rangeland resources and their management is founded on the valueadded concept of navigational ease, focused information, 
screened links and a searchable database along with feedback opportunities. It is intended to serve the general public: students in grades K-12, institutions of higher learning, professional practitioners, industry stakeholders, government agencies, and policy makers.

\section{Touring Arizona AgNIC}

Starting with the URL [http://ag.arizona.edu/agnic/range.html], the user sees the following home page:

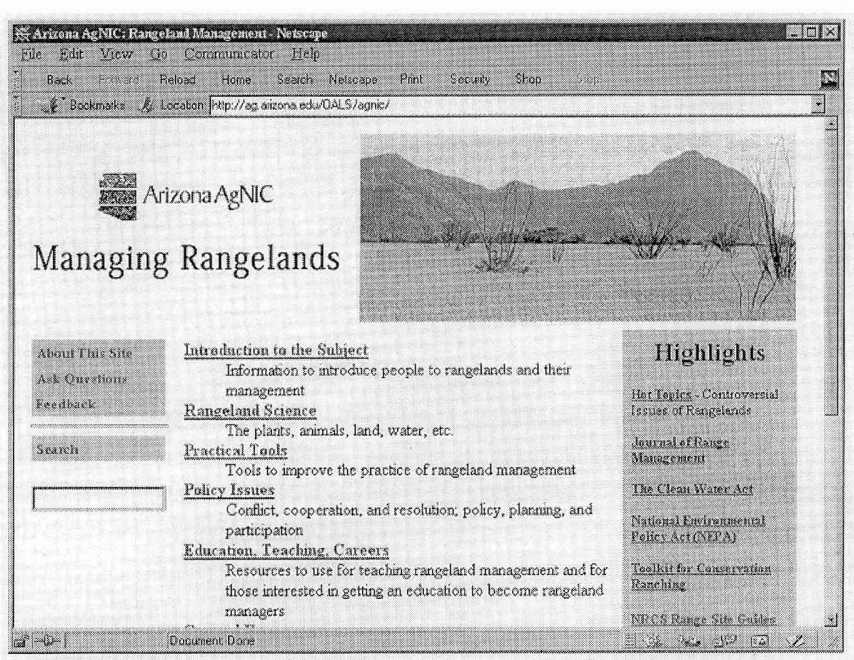

Besides a section that contains general introductory information about the subject, there are five main categories which include the majority of the site's resources: Rangeland Science, Practical Tools, Policy Issues, and Education, Teaching and Careers. The right side panel provides a list of special highlighted resources contained in the Web site, while the left side panel gives the user opportunities to learn more about the site and its developers, to search the site, to ask a specific question, and to provide feedback.

\section{Navigating the Web Site}

On subsequent pages two icons are used throughout the site to signify whether or not the section was developed by Arizona AgNIC. For instance, if a miniature of the Arizona AgNIC symbol is seen, it indicates that the link is to pages the AgNIC team has prepared. Links with the offramp sign take users to sites prepared by other people and organizations.

After leaving the Home Page, the user will notice the blue navigational bar at the top of each page which includes links to every other major section of the site. The Arizona AgNIC symbol at the top and bottom of each locally developed page is a hot link that will always take the user back to the Managing Rangelands Home Page. If leaving the site via an "off-ramp" page, the user will need to use the browser's back button/arrow to return to the Managing Rangelands Home Page.

\section{Web Site Sections}

\section{Rangeland Science}

This section is oriented toward the scientific study of rangelands, their understanding and management. Topics on the main page are specified in several different ways. Under the "general" topic are Special Resources which usually feature those resources created especially for the site by University of Arizona project personnel, but may also include links to particularly noteworthy Web resources compiled elsewhere. The Other Information section most often links to other related sites on the Web.

Of particular interest to Arizona's citizens are the Ecological Site Descriptions specific to Land Resource Units (LRUs) which are designated throughout Arizona. In collaboration with the Arizona State Natural Resources Conservation Service (NRCS), a user-friendly interface is being developed that makes it pessible to search for and identify unique Ecological Site Guides for particular land areas. Two search modes are possible: 1) attribute (elevation, slope, precipitation, and LRU); and 2) geographic (maps with geographic information system capabilities). Based primarily on soils and climate these Guides provide information on the potential of the land to produce vegetation and support various resource uses including grazing. As with much of this Web site, the project is ongoing. Future plans include adding Ecological Site Guides for other states in the Western U.S. and making them searchable following the Arizona model.

The Santa Rita Experimental Range Web site provides data and repeat photography from the first experimental range in the United States, founded in 1903, and located south of Tucson. The photos demonstrate changes in vegetation through the years from various locations on the 53,159 acre research facility.

Other resources are organized by specific topics and can be reviewed by clicking on the topic of choice as noted in the bar at the top: AnimalsIClimatelLand|Plants|Water. These include links to both Arizona AgNIC and non-Arizona AgNIC Web sites with applications in these areas.

\section{Practical Tools}

The main page for the section on Practical Tools also is organized similarly to Rangeland Science. At the top are those resources which hold promise for helping users answer questions of a practical nature that can lead to new and better management strategies. Here you can find links to information on noxious weeds, rangeland health standards, and other management related topics.

Also included is the Toolkit for Profitable Conservation Ranching. This sub-section was prepared in cooperation with the Arizona Common Ground Roundtable, a state-wide group of ranchers, environmentalists, researchers, public agency personnel, sportsmen, and other interested citizens seeking to identify tools and policy changes that will conserve open spaces. (See their Web site at:

[http://udallcenter.arizona.edu/commonground/]). Original texts and links provide information on how to preserve open 
space through such means as conservation easements, land trusts and family trusts. In addition, alternative forms of income generation for ranches are discussed, such as guest ranches, summer camps, and fee hunting. The toolkit also includes information on finding legal assistance and supplemental grants and funding opportunities.

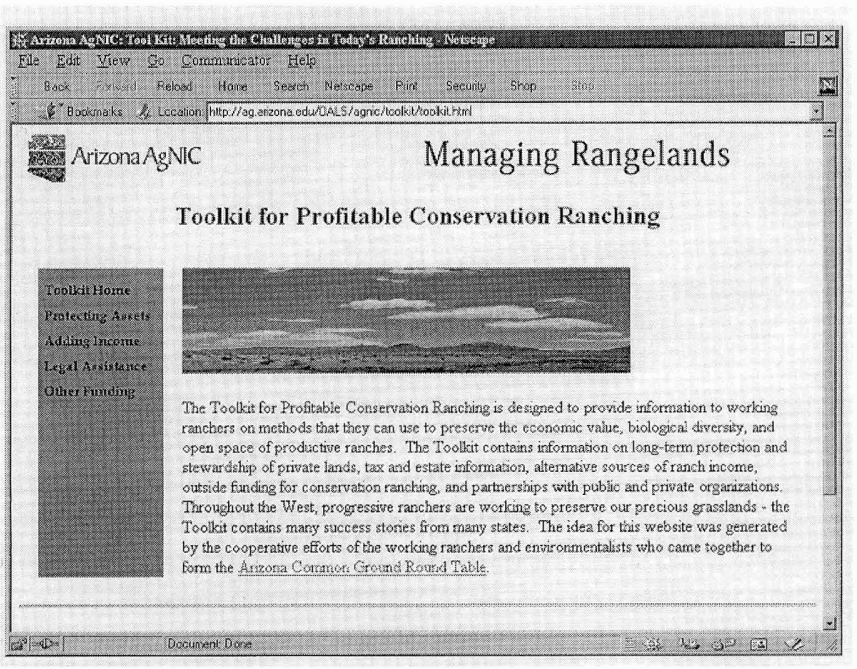

\section{Policy Issues}

Managing the rangelands of the western United States involves many different people, groups, and agencies with differing points of view. Issues surrounding the preservation, conservation, and fair use of rangelands are often controversial and seem intractable. The resolution of those conflicts involves developing a constructive dialog based on finding common ground and areas of compromise. This section of the Web site focuses on aspects of the policy and political issues regarding rangelands.

Beginning with a link to a pictorial representation of eight "hot topics", the user can find links to other Web sites on the subjects: Indian Lands, Urbanization, Water and Riparian

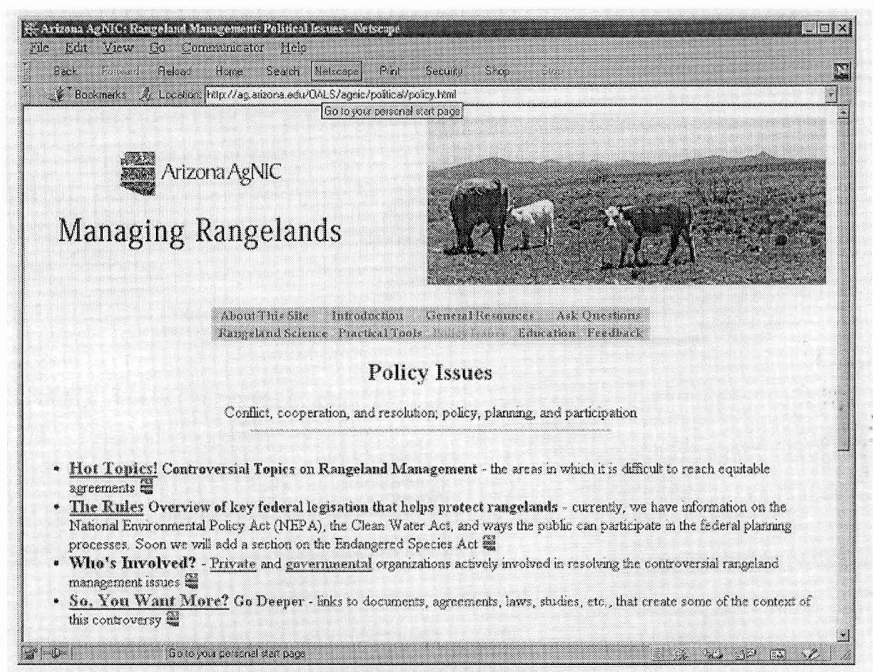

Areas, Recreation, Mining, Logging, Grazing on Public Lands, and Wildlife and Endangered Species. Each of these topics is divided into three categories providing background information, newspaper items, and information on legal issues.

"The Rules" section provides an in-depth review of the National Environmental Policy Act (NEPA) and other federal regulations, and a discussion of how NEPA is implemented by various agencies and interpreted by the courts. In addition, a section describing the Clean Water Act and how it relates to rangeland issues was recently added. The final section in this category provides announcements of opportunities for public participation in rangeland resource management issues.

\section{Education, Teaching, and Careers}

To assist teachers and students in their academic pursuits, this section provides links to potentially useful teaching materials, lists of college programs in rangeland management, and guidance in planning for a career in this field. In particular, faculty in the Rangeland Program at the University of Arizona are preparing an online textbook for the site titled, Principles of Rangeland Science and Management. At the time of this publication, Chapter 4 (Ecology and Management of Rangeland Vegetation) and Chapter 5 (Rangeland Inventory and Monitoring) are in place. Within these chapters are links to further explanations and to related readings.

\section{General Resources}

Links are found in the General Resources section to academic institutions with rangeland programs, selected Extension publications, online bibliographic databases, online journals, meeting announcements, government and non-government organizations, directories of expertise, and related listservs. Of particular importance, project staff from the University of Arizona Library have worked with the Society for Range Management to digitize the print backfiles (Volumes 1-47, 1948-1994) of the Journal of Range Management, and make them available through this Web site. Individual articles can be printed out by selecting a given title highlighted on the Table of Contents page.

\section{Ask Questions (Left Side Panel)}

The Web site provides an interactive form in this section for questions about rangelands. First-time users should read the Frequently-Asked-Questions (FAQ) about this reference service, linked at the top of the form.

Individuals using the query form should fill out all five sections, with their name, email address, occupation and affiliation, the question and additional information that will provide context for the question. A response to the question is usually provided within 24 hours. 


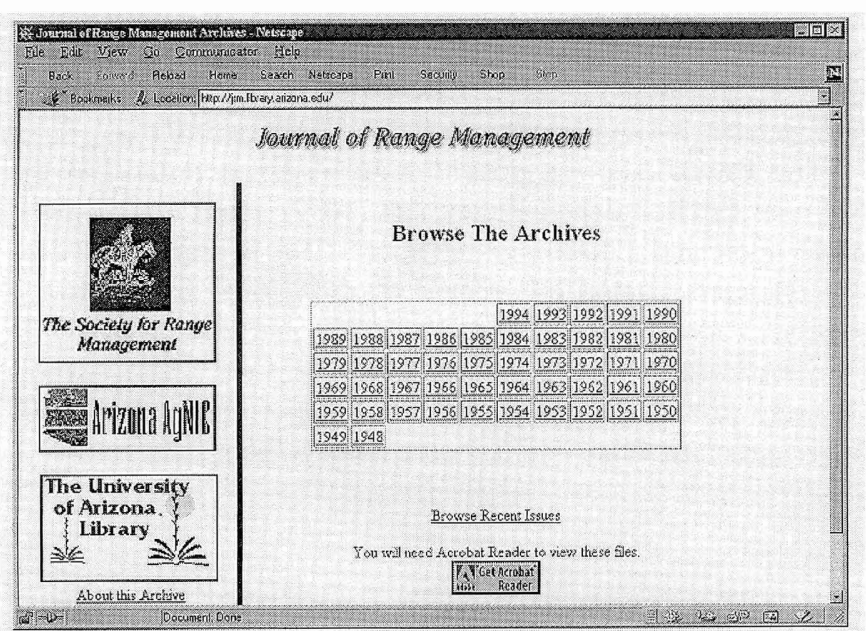

\section{Feedback From Users}

The project team for the Managing Rangelands Web site is committed to improving the site and making it more useful. The interactive feedback form gives users the opportunity to evaluate the site and make suggestions such as additional sites to link to or further, topic-specific information.

\section{Searching for Specific Information}

The search function allows users to enter words, phrases, or combination of words using Boolean operators (and, or, not) to find specific locations where those words are mentioned on the Managing Rangelands Web site. It provides a means to rapidly locate specific information or resources.

\section{Conclusion}

The Arizona AgNIC Managing Rangelands Web site is very much a work in progress. By continuing to submit proposals for grants to support the development of particular aspects and tools for the site, the Arizona AgNIC team plans to make many more enhancements to improve usability. The team also solicits feedback from interested Web users.

The authors are librarian, Office of Arid Land Studies and range management specialist, School of Renewable Natural Resources, The University of Arizona, Tucson, Arizona 85721.

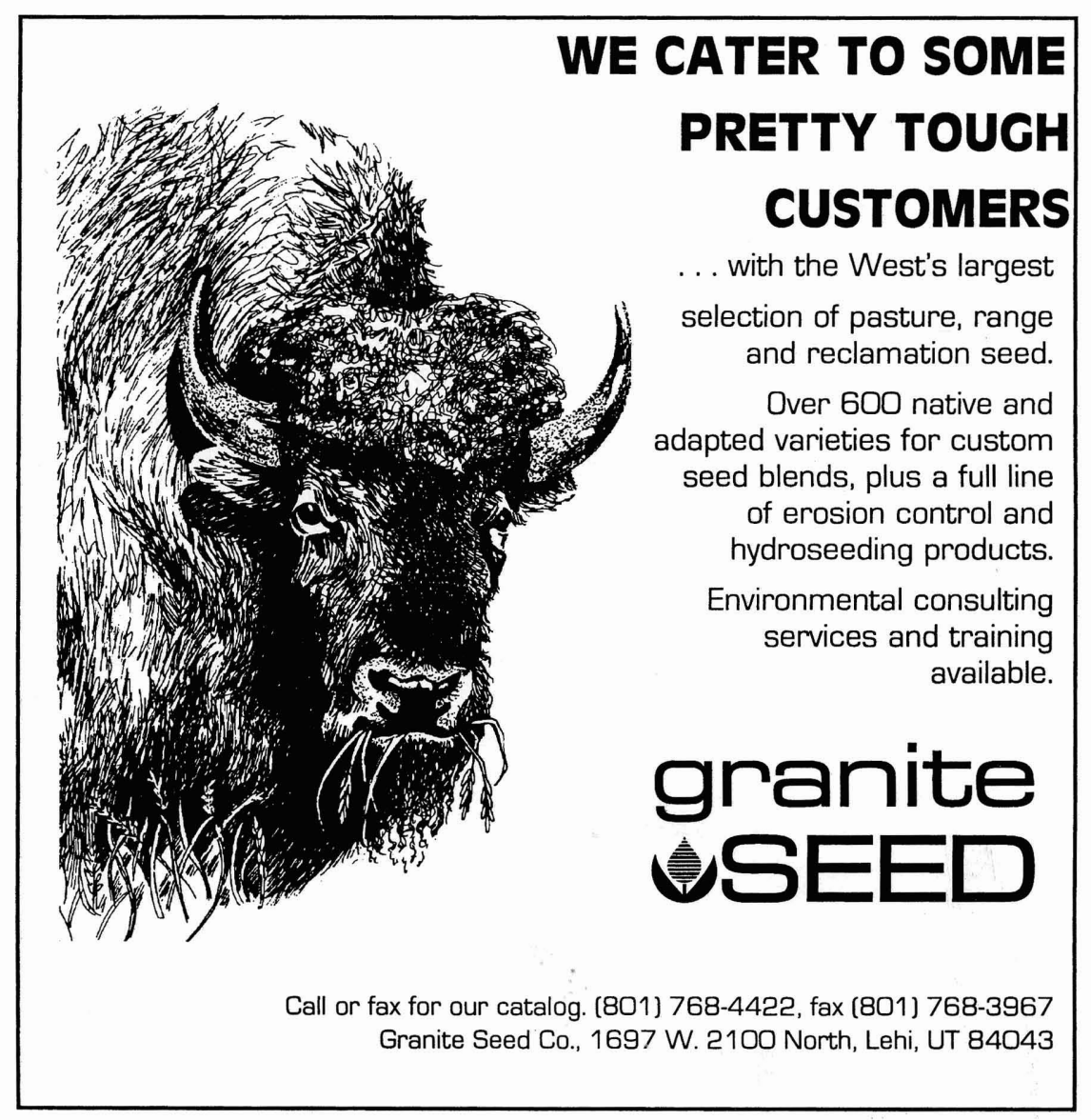

